\title{
Verapamil and the myocardium
}

\author{
WiNIFRED G. NAYLER \\ D.Sc.
Cardiothoracic Institute,
2 Beaumont Street, London, $W .1$

\begin{abstract}
Summary
Although many of the drugs which recently have been developed for use in relieving angina pectoris display $\beta$-adrenoceptor blocking activity this property cannot be essential, because verapamil relieves angina pectoris without blocking the cardiac $\beta$-adrenoceptors. Like propranolol, verapamil slows the heart and reduces both the peak tension developed during systole and the rate at which that tension is developed. Verapamil further resembles propranolol in that it improves cardiac efficiency, reduces the oxygen requirement of the heart and abolishes certain arrhythmias. Verapamil differs from propranolol, however, in that it does not antagonize the cardiac $\beta$-adrenoceptors and it dilates the coronary vessels. Verapamil probably owes its activity to its ability to interfere with the inwards displacement of calcium ions across cardiac cell membranes.
\end{abstract}

MANY of the drugs which have been developed during the past decade for use in the relief of angina pectoris have proved useful for the treatment of cardiac arrhythmias. Some of these compounds, e.g. propranolol, oxprenolol and pindolol, exhibit $\beta$-adrenoceptor blocking activity but others-for example veraoamil (Nayler et al., 1968a; Livesley et al., 1973; Krikler, 1974) do not. The mode of action of these newly developed drugs is perhaps most easily explained if it is discussed in terms of the sequence of events which are involved in the contractionrelaxation cycle of cardiac muscle (Langer, 1968; Nayler, 1974) as well as in terms of the main determinants of myocardial oxygen consumption (Sarnoff et al., 1958; Braunwald, 1971). This in turn requires an understanding of the subcellular organization of the cardiac muscle cell.

In cardiac as in skeletal muscle the fundamental unit of muscle structure is the sarcomere, defined as the distance between two adjacent $\mathrm{Z}$ bands. $\mathrm{Z}$ bands are easily visible in the electromicrograph shown

Correspondence: Dr Winifred G. Nayler, Cardiothoracic Institute, 2 Beaumont Street, London, W1N 2DX.

\author{
DENNIS KRIKLER \\ M.D., F.R.C.P., F.A.C.C. \\ Cardiovascular Division, Royal Postgraduate \\ Medical School, Hammersmith Hospital, \\ London, W.12
}

in Fig. 1. Within each sarcomere the contractile proteins are arranged to form a regular, but interdigitating array of thick (myosin) and thin (actin) filaments (Huxley, 1969). Contraction involves the regulated displacement of the actin along the relatively thicker myosin filaments such that whilst the length of each actin and each myosin filament remains constant the distance between adjacent $\mathrm{Z}$ bands changes. The displacement of the actin along the myosin filaments is a complex process (Katz, 1971) requiring the sequential formation and activation of cross-bridges between the adjacent filaments. Energy for the formation and activation of these cross-bridges is derived from the hydrolysis of adenosine triphosphate (ATP). The relevant ATPase enzyme forms part of the myosin molecule. It is $\mathbf{M g}^{2+}$-dependent and is activated by both actin and $\mathrm{Ca}^{2+}$. The $\mathrm{Ca}^{2+}$-induced activation of the myosin ATPase enzyme is indirect and complex. It involves an interaction between $\mathrm{Ca}^{2+}$ and the regulatory proteins (Katz, 1971; Nayler, 1974) within the myofilaments, as shown schematically in Fig. 2.

When $\mathrm{Ca}^{2+}$ is either absent or its concentration falls below a critical level these regulatory proteins (troponin and tropomyosin) prevent actin from activating the myosin ATPase enzyme (Ebashi and Endo, 1968). When sufficient $\mathrm{Ca}^{2+}$ becomes available, however, then this inhibiting effect of the regulatory proteins is suppressed and accordingly the actin-induced activation of the myosin ATPase enzyme can proceed. Now, provided that sufficient ATP is available for hydrolysis, that the myosin ATPase is active and that its various co-factors, including $\mathrm{Mg}^{2+}$, are present, then, as shown schematically in Fig. 3, the transition from diastole to systole depends simply upon an increase in the intracellular availability of $\mathrm{Ca}^{2+}$. When the intracellular $\mathrm{Ca}^{2+}$ concentration exceeds a critical level of approximately $10^{-7} \mathrm{M}$ the rate at which the myosin ATPase enzyme hydrolyses ATP is probably just sufficient (Weber and Herz, 1963) to provide the high energy phosphate bonds needed to facilitate cross-bridge formation and activation. Under conditions such as these the 


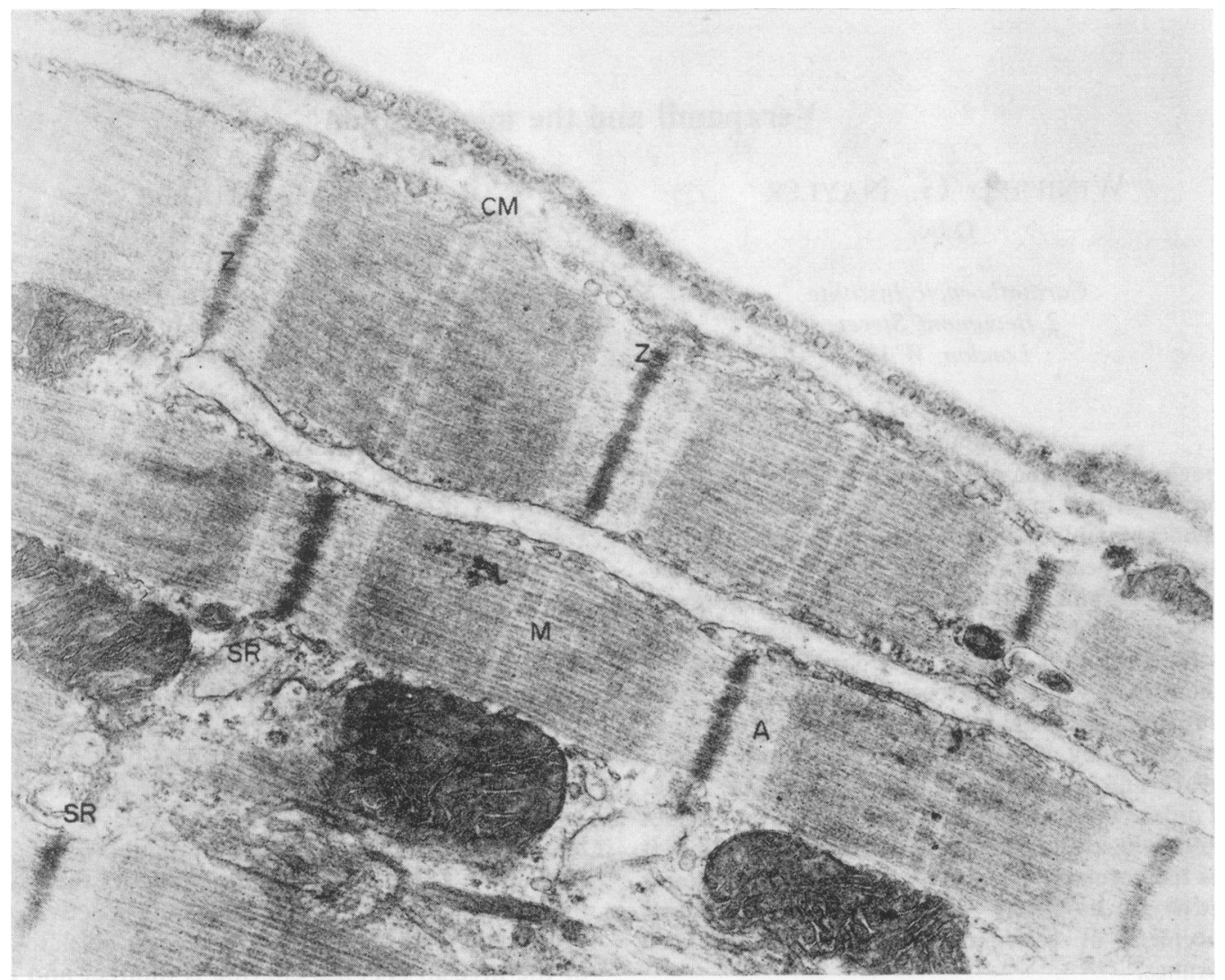

Fig. 1. Electromicrograph of part of the heart muscle cell. Note the $Z$ bands, actin and myosin filaments, the sarcoplasmic reticulum and the cell membrane. $(\times 28,000$. $) Z=Z$ band; $M=$ myosin; $A=$ actin; $\mathrm{SR}=$ sarcoplasmic reticulum; $\mathrm{CM}=$ cell membrane.

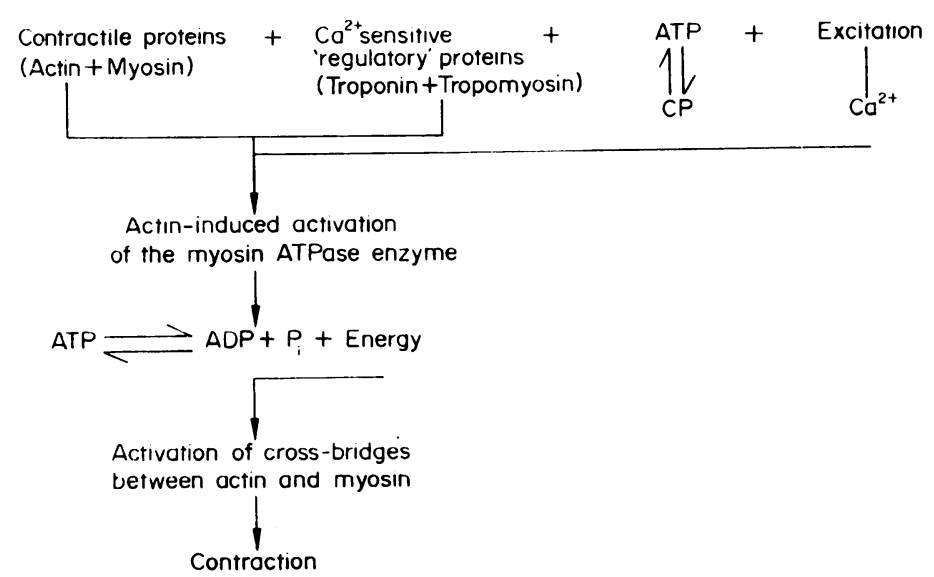

Fig. 2. Schematic representation of the events involved in the activation of contraction. 


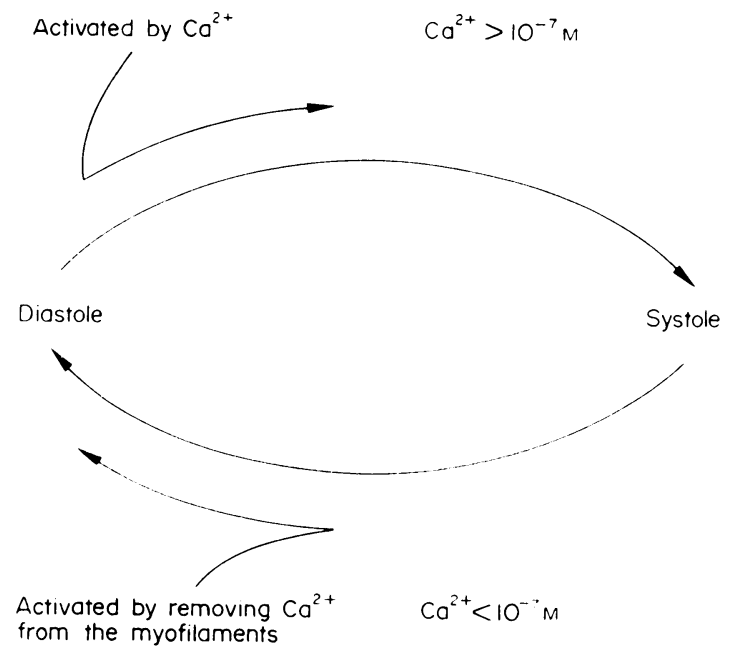

FIG. 3. Schematic representation of the involvement of $\mathrm{Ca}^{2+}$ in the systole $\rightarrow$ diastole $\rightarrow$ systole cycle in heart muscle.

rate at which the muscle develops tension and undergoes shortening depends largely upon the intracellular availability of $\mathrm{Ca}^{2+}$, because this regulates the rate of ATP hydrolysis. The transition from systole to diastole reflects the reverse phenomenonthat is a reduction in the intracellular availability of $\mathrm{Ca}^{2+}$ (Schwartz, 1971) such that the regulatory proteins, troponin and tropomyosin, can re-exert their inhibitory effect on the actin-reduced activation of the myosin ATPase enzyme.

Because of the relative importance of the role which $\mathrm{Ca}$ ions play in regulating the transition from diastole $\longrightarrow$ systole $\longrightarrow$ diastole, shown schematically in Fig. 3, it is not surprising to find that considerable effort has been expended in experiments aimed at establishing how the intracellular availability of $\mathrm{Ca}^{2}+$ is regulated to facilitate either contraction or relaxation as exhibited in the cardiac cycle. These studies have shown that resting heart muscle cells have a potential difference of approximately 90 $\mathrm{mV}$, the inside being negative with respect to the outside, and that the reversal of this transmembrane potential difference, such as that which (Fig. 4) occurs during the rising phase of a cardiac action potential, is accompanied by the influx of $\mathrm{Ca}^{2+}$ as well as $\mathrm{Na}^{+}$ (Nayler and Merrillees, 1971). Some of the $\mathrm{Ca}^{2+}$ which is involved in this influx is derived from the extracellular phase but some of it is probably displaced inwards from superficially located storage sites associated with the polysaccharides in the basement coat of the cell membrane (Langer, 1971; Nayler, 1973). When displaced inwards some of these $\mathrm{Ca}$ ions may activate contraction directly, but some of them probably function as a 'transmitter-like'

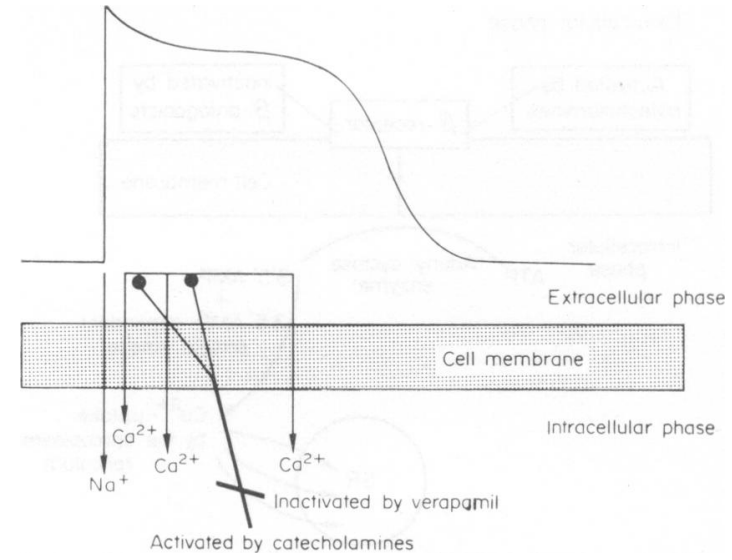

FIG. 4. Schematic representation of the $\mathrm{Ca}^{2+}$ and $\mathrm{Na}^{+}$ influx associated with the rising and plateau phases of the cardiac action potential. Note that verapamil impedes the influx of $\mathrm{Ca}^{2+}$

substance, evoking the release of more $\mathrm{Ca}^{2}+$ from intracellular storage sites. These intracellular storage sites are almost certainly associated with the sarcoplasmic reticulum, that fine lace-like network of tubules seen in Fig. 1, and which envelopes the myofibrils, crossing from sarcomere to sarcomere and coming into close proximity to the cell membrane and its intracellular ramifications (Porter, 1961). This subcellular organelle can accumulate and store $\mathrm{Ca}^{2+}$ against a considerable concentration gradient (Schwartz, 1971). Presumably, therefore, it serves a dual function:

(a) to provide a source of $\mathrm{Ca}^{2+}$ which can be released into the vicinity of the myofibrils to facilitate contraction;

(b) to provide a mechanism for retrieving $\mathrm{Ca}^{2+}$ from the sarcoplasm, to facilitate relaxation.

That the catecholamines increase both the peak tension developed during contraction and the rate at which that tension develops is now firmly established. These catecholamine-induced changes in contractility almost certainly can be accounted for in terms of an increase in the amount of $\mathrm{Ca}^{2+}$ (Shigenbou and Sperelakis, 1972) which enters the cell during the rising and plateau stages of the action potential, shown schematically in Fig. 4. Whether this catecholamine-induced increase in the amount of $\mathrm{Ca}^{2+}$ which becomes available for interaction with the myofibrillar proteins results from the activation of a membrane-located adenyl cyclase enzyme is not yet firmly established, but it is known that cardiac cell membranes contain an active adenyl cyclase enzyme capable of converting ATP to 3' 5' AMP (Rubio, Berne and Dobson, 1973), and that under certain conditions 3' 5' AMP facilitates the transfer of $\mathrm{Ca}^{2+}$ across isolated membranes (Kirchberger et al., 1972). 


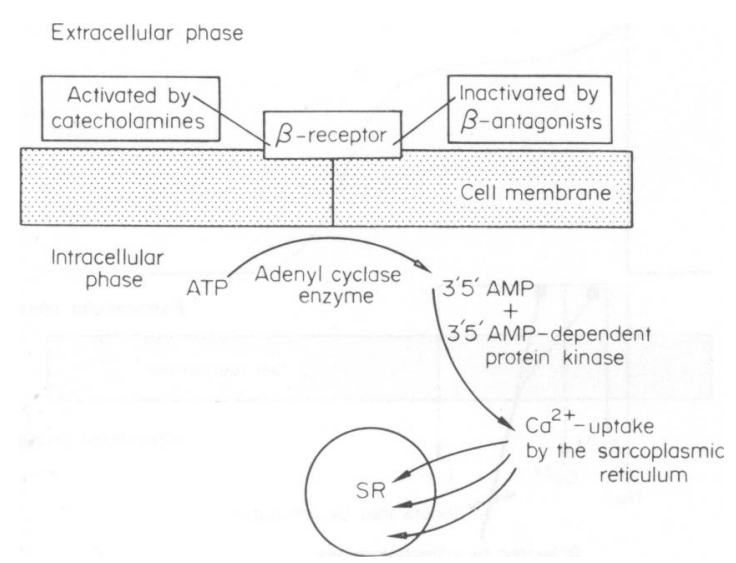

FIG. 5. Schematic representation of the pathways involved in activation by $\beta$-adrenoceptor agonists and inactivation by $\beta$-adrenoceptor antagonists of the adenyl cyclase enzyme. Note that in the presence of the $3^{\prime} 5^{\prime}$ AMP-dependent kinase $3^{\prime} 5^{\prime}$ AMP facilitates the uptake of $\mathrm{Ca}^{2+}$ by the sarcoplasmic reticulum.

As well as increasing the peak tension developed during contraction and the rate at which that tension is developed the catecholamines accelerate the transition from systole to diastole. Recent studies (Katz and Repke, 1973) have shown that this catecholamine-induced increase in the rate at which cardiac muscle undergoes relaxation may be due to a 3' 5' AMP-dependent increase in the rate at which $\mathrm{Ca}^{2+}$ is accumulated by the sarcoplasmic reticulum. The scheme of events which may be involved in this process is shown schematically in Fig. 5. By activating the adenyl cyclase enzyme the catecholamines increase the intracellular availability of $3^{\prime} 5^{\prime}$ AMP and therefore, indirectly, increase the rate at which $\mathrm{Ca}^{2+}$ is accumulated by the sarcoplasmic reticulum. This in turn should facilitate the transition from systole $\rightarrow$ diastole.

The presently available $\beta$-adrenoceptor antagonists block many of these catecholamine-induced changes and therefore can be used clinically to protect the myocardium against the effects of excessive sympathetic stimulation (Nayler and Carson, 1973). These effects of sympathetic stimulation include, in addition to the enhanced contractile force and rate of tension development, an increase in heart rate (Braunwald and Chidsey, 1965). When it is recalled that the main determinants of myocardial oxygen consumption (Sarnoff et al., 1958; Braunwald, 1971) include rate of tension development, the peak tension developed during systole and heart rate (Table 1) then it is not altogether surprising to find that $\beta$-adrenoceptor antagonists are useful in limiting the myocardial demand for oxygen (Hamer, 1968; Nayler and Carson, 1973) and therefore have proved useful for the treatment of angina pectoris. The presently avail- able $\beta$-adrenoceptor antagonists generally increase the overall efficiency with which the heart performs useful mechanical work (Nayler et al., 1967, 1968b). Some of them (Nayler et al., 1967) increase coronary vascular resistance. Because of their $\beta$-adrenoceptor blocking activity, however, they deprive the heart of sympathetically-mediated support.

The use of $\beta$-adrenoceptor antagonists as antiarrhythmic compounds largely reflects their ability to protect the heart against the effects of excessive neurotransmitter release (Vaughan Williams, 1972). However, some of this antiarrhythmic activity, particularly when high dose levels are established, may involve the ability of these drugs to interact with the cell membrane in such a way as to render that membrane less permeable to various ions, including $\mathrm{Na}^{+}$ and $\mathrm{Ca}^{2+}$ (Nayler et al., 1969). Interaction with the cell membrane to limit its permeability to $\mathrm{Ca}^{2}+$ is not the prerogative of $\beta$-adrenoceptor blocking drugs; for example the drug verapamil, which although devoid of $\beta$-adrenoceptor blocking activity, is useful for the relief of angina pectoris and the relief of certain arrhythmias (Singh and Vaughan Williams, 1972; Krikler, 1974) and owes its activity to its ability to impede the entry of $\mathrm{Ca}^{2}+$ into the cardiac muscle cell (Fleckenstein, 1971; Nayler and Szeto, 1972).

Like propranolol (Table 2) verapamil decreasese cardiac contractility and heart rate (Nayler et al.,? 1968a). Like propranolol, therefore, it decreases the myocardial demand for oxygen (Nayler and Szeto, 1972). However, in marked contrast to propranolol (Nayler et al., 1967) verapamil reduces coronary vascular resistance (Nayler et al., 1968a). Both drugs increase the efficiency with which the heart performs useful mechanical work (Nayler et al., 1968a and b; Nayler and Szeto, 1972). These effects of propranolol and verapamil are summarized in Tables 1 and 2 . Despite the similarities which exist between these drugs verapamil differs from either propranolol,

TABLE 1. Effect of drugs on myocardial oxygen consumption and cardiac efficiency

\begin{tabular}{lccc}
\hline & Verapamil & Propranolol & Noradrenaline \\
\hline $\begin{array}{l}\text { Myocardial } \mathrm{O}_{2} \\
\text { consumption }\end{array}$ & $\downarrow$ & $\downarrow$ & $\uparrow$ \\
$\begin{array}{l}\text { Cardiac } \\
\text { contractility }\end{array}$ & $\downarrow$ & $\downarrow \downarrow$ & $\uparrow$ \\
$\begin{array}{l}\text { Coronary blood } \\
\text { flow }\end{array}$ & $\uparrow$ & $\downarrow$ & $\downarrow$ then $\uparrow$ \\
$\begin{array}{l}\text { Heart rate } \\
\begin{array}{l}\text { Cardiac } \\
\text { efficiency }\end{array}\end{array}$ & $\downarrow$ & $\downarrow$ & $\uparrow$ \\
\hline
\end{tabular}

Where $\uparrow$ denotes an increase and $\downarrow$ a decrease. 
TABle 2. Effect of drugs on contraction and relaxation in heart muscle stimulated to contract at a regular rate

\begin{tabular}{|c|c|c|c|}
\hline Drug & Verapamil & Propranolol & Noradrenaline \\
\hline $\begin{array}{l}\text { Peak developed } \\
\text { tension }\end{array}$ & $\downarrow$ & $\vdots$ & $\uparrow$ \\
\hline $\begin{array}{c}\text { Rate of tension } \\
\text { development }\end{array}$ & ' & ! & $i$ \\
\hline $\begin{array}{l}\text { Time required for } \\
\text { relaxation }\end{array}$ & $\hat{\imath}$ & 3 & $\downarrow$ \\
\hline
\end{tabular}

Where $\uparrow$ denotes an increase and a decrease.

oxprenolol, or pindolol in that it neither deprives the heart of sympathetic support nor does it interfere with the adenyl cyclase enzyme. Probably verapamil represents the first of a new and exciting series of drugs which may be useful for relieving angina pectoris (Sandler, Clayton and Thornicroft, 1968; Nyberg, 1973) and arresting cardiac arrhythmias. The action of verapamil almost certainly can be accounted for in terms of its ability to react with superficially-located $\mathrm{Ca}^{2+}$ storage sites in heart muscle cells, so that when the cell membrane is depolarized fewer $\mathrm{Ca}$ ions will be displaced inwards into the vicinity of the myofilaments. Accordingly the myocardial demand for oxygen is reduced (Nayler and Szeto, 1972) and arrhythmias reversed (Schamroth, 1971; Schamroth et al., 1972).

\section{References}

Braunwald, E. (1971) Control of myocardial oxygen consumption. Physiologic and clinical considerations. The American Journal of Cardiology, 27, 416.

Braunwald, E. \& Chidsey, C.A. (1965) The adrenergic nervous system in the control of the normal and failing heart. Proceedings of the Roval Society of Medicine, 58, 1063.

Ebashi, S. \& Endo, M. (1968) Calcium ion and muscle contraction. Progress in Biophysics and Molecular Biology, 18, 123.

Fleckenstein, A. (1971) Specific inhibitors and promoters of calcium action in the excitation-contraction coupling of heart muscle and their role in the prevention or production of myocardial lesions. In: Calcium and the Heart (Ed. by P. Harris and L. H. Opie), p. 135. Academic Press, London.

HAMER, J. (1968) Cardiac work. British Heart Journal, 30, 443.

HUXLEY, H.E. (1969) The mechanism of muscle contraction. Science, 164, 1356.

KATZ, A.M. (1971) Calcium and the cardiac contractile proteins. In: Calcium and the Heart (Ed. by P. Harris and L. H. Opie), p. 124. Academic Press, London.

KATZ, A.M. \& REPKE, D. (1973) Calcium-membrane interactions in the myocardium. Effects of ouabain, epinephrine and $3^{\prime} 5^{\prime}$ AMP. The American Journal of Cardiology, 31, 193.

Kirchberger, M.A., Tada, M., Repke, D.I. \& Katz, A.M. (1972) Cyclic 3' 5' adenosine monophosphate-dependent protein kinase stimulation of calcium uptake by canine cardiac microsomes. Journal of Molecular and Cellular Cardiology, 4, 673.

KRIKLER, D. (1974) The role of verapamil in cardiology. European Journal of Cardiology. (In press.)

LANGER, G.A. (1968) Ion fluxes in cardiac excitation and contraction and their relation to myocardial contractility. Physiological Reviews, 48, 708.
LANGER, G.A. (1971) Coupling calcium in mammalian ventricle, its source and factors regulating its quantity. Cardiovascular Research, Suppl. 1, 71.

livesley, B., Catley, P.F., Campbell, R.C. \& Oram, S. (1973) Double blind evaluation of verapamil, propranolol and isosorbide dinitrate against placebo in the treatment of angina pectoris. British Medical Journal, 1, 375.

NAYler, W.G. (1973) An effect of ouabain on the superficially-located stores of calcium in cardiac muscle cells. Journal of Molecular and Cellular Cardiology, 5, 101.

NAYLER, W.G. (1974) The ionic basis of contractility, relaxation and cardiac failure. In: Modern Trends in Cardiology (Ed. by M. Oliver), vol. 3. (In press.)

NAYLER, W.G. \& CARSON, V. (1973) Effect of stellate ganglion stimulation on myocardial blood flow, oxygen consumption, and cardiac efficiency during beta-adrenoceptor blockade. Cardiovascular Research, 7, 22.

Nayler, W.G., McInnes, I., Swann, J.B., Carson, V. \& LowE, T.E. (1967) Effect of propranolol, a beta-adrenergic antagonist, on blood flow in the coronary and other vascular fields. American Heart Journal, 73, 207.

Nayler, W.G., McInnes, I., SWann, J.B., Price, J.M., Carson, V., Race, D. \& Lowe, T.E. (1968a) Some effects of iproveratril (isoptin) on the cardiovascular system. Journal of Pharmacology and Experimental Therapeutics, 161, 247.

Nayler, W.G., McInnes, I., Swann, J.B., Race, D., Carson, V. \& Lowe, T.E. (1968b) Some effects of diphenylhydantoin and propranolol on the cardiovascular system. American Heart Journal, 75, 83.

NAYLer, W.G. \& MerRilleES, N.C.R. (1971) Cellular exchange of calcium. In: Calcium and the Heart (Ed. by P. Harris and L. H. Opie), p. 24. Academic Press, London.

Nayler, W.G., Stone, J., Carson, V., McInnes, I., Mack, V. \& LowE, T.E. (1969) The effect of beta adrenergic antagonists on cardiac contractions, myofibrillar ATPase activity, high-energy phosphate stores and lipid-facilitated transport of calcium ions. Journal of Pharmacology and Experimental Therapeutics, 165, 225.

NAYLER, W.G. \& SzETo, J. (1972) Effect of verapamil on contractility, oxygen utilization and calcium exchangeability in human heart muscle. Cardiovascular Research, 6 , 120.

NyBERG, G. (1973) Drugs for angina pectoris. British Medical Journal, 3, 47.

PORTER, K.R. (1961) The sarcoplasmic reticulum. Its recent history and present status. Journal of Biophysical and Biochemical Cytology, 10, supp. 4, 219.

Rubio, R., Berne, R.M. \& Dobson, J.G. (1973) Sites of adenosine production in cardiac and skeletal muscle. American Journal of Physiology, 225, 938.

Sandler, G., Clayton, G.A. \& Thornicroft, S.G. (1968) Clinical evaluation of verapamil in angina pectoris. British Medical Journal, 3, 224.

Sarnoff, S.J., Braunwald, E., Welch, G.H., Case, R.B., Stainsby, W.N. \& MaCrUZ, R. (1958) Haemodynamic determinants of oxygen consumption of the heart with special reference to the tension-time index. American Journal of Physiology, 192, 148.

Schamroth, L. (1971) Immediate effects of intravenous verapamil on atrial fibrillation. Cardiovascular Research, 5, 419.

Schamroth, L., Krikler, D.M. \& Garrett, C. (1972) Immediate effects of intravenous verapamil in cardiac arrhythmias. British Medical Journal, 1, 660.

Schwartz, A. (1971) Calcium and the sarcoplasmic reticulum. In: Calcium and the Heart (Ed. by P. Harris and L. H. Opie), p. 66. Academic Press, London.

Shigenbou, K. \& Sperelakis, N. (1972) Calcium current channels induced by catecholamines in chick embryonic 
hearts whose fast sodium channels are blocked by tetrodotoxin or elevated potassium. Circulation Research, 31, 932.

Singh, B.N. \& Vaughan Williams, E.M. (1972) A fourth class of antidysrhythmic action. Effect of verapamil on ouabain toxicity, on atrial and ventricular action potentials and on other features of cardiac function. Cardiovascular Research, 6, 109.
VaughaN Williams, E.M. (1972) Biophysical background to beta blockade. In: New Perspectives in $\beta$-Blockade, p. 11. Published by Ciba Laboratories, Horsham, England.

Weber, A. \& Herz, R. (1963) The binding of calcium to actomyosin systems in relation to their biological activity. Journal of Biological Chemistry, 238, 599. 